\title{
Metalinguistic Awareness of Multilingual First Graders: An Exploratory Study
}

\author{
${ }^{1}$ Irish Mae Fernandez-Dalona, ${ }^{2}$ Alvert Dalona
}

1,2 MSU-Iligan Institute of Technology, Iligan City, Philippines,

irishmae.fernandez@g.msuiit.edu.ph alvert.dalona@g.msuiit.edu.ph

\begin{abstract}
This study, which utilized a modified metalinguistic awareness test adopted from Dita's (2009), probed on young children's metalinguistic awareness in identifying syntactic errors; determining sounds and the use of phonological segments; and explaining a word on their own by describing its appearance or its functions in English, Filipino, and Cebuano. This study attempted to elucidate young children's readiness to take on more difficult linguistic tasks in the succeeding academic levels. Since the children's level of metalinguistic awareness is average, this study recommends that schools are encouraged to provide strategies and lessons that would enhance learners' metalinguistic awareness, most especially in terms of language arbitrariness in English and Filipino; and since there is significant difference in all three languages in all tests, parents and teachers should ensure that the pupils achieve full proficiency in all three languages by providing rich experiences equally in these languages.
\end{abstract}

Keywords: metalinguistic awareness, bilingualism, multilingualism

How to Cite: Dalona, I.M.F. \& Dalona, A. (2019). Metalinguistic awareness of multilingual first graders: An exploratory study. English Language Teaching Education Journal, 2(3), 102-111

\section{INTRODUCTION}

Bilingual/Multilingual Education has been the subject of never ending debate as to its possible harm or gain. One of the strongest defenses to promoting bilingualism/ multilingualism is that "in contrast to monolinguals, bilinguals develop communicative sensibility, creativity and metalinguistic awareness" (Goetz, 2003). Metalinguistic awareness refers to an individual's understanding that language is a system of communication, which follows certain rules; and the rules become the basis for the ability to discuss different ways to use language (Baten, Hofman \& Loeys, 2011). An individual with such ability is aware that linguistic forms and structure can be framed and manipulated to communicate a variety of meanings. In Thailand, a study was conducted to test children's metalinguistic awareness to determine whether bilingualism inhibit their learning or not. The study shows that monolinguals and sequential bilinguals do not differ. Importantly, bilingualism does not affect the development of their first language (L1).

In the present educational system in the Philippines, young school-age children are tasked to read and write in English and Filipino, the Philippine's national language. This can pose a bigger challenge to those whose first language is neither Filipino nor English. Dita (2009) conducted a study in the northern part of Philippines to test the metalinguistic awareness of Filipino bilingual children, foci of which is on: (a) Language Arbitrariness, which demands the ability of a person to recognize correct syntactic errors; (b) Phonological Awareness, which demands the capability of a person to identify sounds and use phonological segments; and (c) Vocabulary, which demands the ability of a person to explain a word on his own by describing its appearance or its functions. Her investigation revealed that full bilinguals outscored the partial bilinguals in the entire test conducted suggesting that those children who were proficient on two or more languages perform multilingual tasks better than the monolinguals.

Since the Philippines is now facing a new educational system which supports the use of mother languages, and classes are getting more culturally and linguistically diverse, schools should discern whether learner's knowledge is adequate to face the demands of the succeeding academic levels. This, therefore, motivated the researchers to conceptualize this study, which particularly focuses on bilingual children in an Elementary School in Davao City, Philippines, which is home to various linguistic communities, especially Cebuano, and where English and Filipino are encouraged mediums of instruction in schools.

Specifically, this is sought to provide answers to the following:

1. What is the level of students' Metalinguistic awareness in English, Filipino and Cebuano? 
2. Is there a significant difference between the students' level of metalinguistic awareness in English, Filipino, and Cebuano in terms of language arbitrariness, phonological awareness, and vocabulary?

3. What can be deduced about language instruction at the basic education level in the country?

This study is deemed important as it shed light on the linguistic proficiency of young learners and their capacity to perform linguistic tasks as they continue their academic pursuits.

Bilingualism is the ability of a person to speak two languages: the frequent oral use of two languages and multilingual ability of a person to use several languages. However, the distinction of multilingualism and bilingualism has been greatly argued. In the study of Wachira (2006) on the multilingualism in Kenya she discussed the relevance of multilingualism and bilingualism. She cited that bilingualism occurs when a given society two or more languages are spoken. As cited in Grosjean and Li (2013), Haugen (1956) defines a bilingual, as a "bilinguist" or as one who knows two languages or more than two (languages). Some refer to them as a pluralingual, a multilingual, or a polyglot. Therefore, based on this definition, bilinguals and multilinguals are technically the same, i.e. those who can use more than one language. As defined by Grosjean and Li (2013), bilingualism is a regular use of two (or more) languages. Thus, bilingualism and multilingualism have similar concepts. An individual who has the capacity to function in two or more languages in muticultural communities at an equal level of proficiency with native speakers and in accordance with the sociocultural demands for communicative and cognitive competence by these communities, (Skutnabb-Kangas, 1984), can either be a bilingual or a multilingual.

Metalinguistic awareness, on the other hand, is the ability of an individual to analyze the subparts of any language, and to understand how every component of a language operates and how they are incorporated into the wider linguistic system (Beceren, 2010). According to Tunmer and Cole (1985), in Hill (1998), metalinguistic awareness is the ability to deliberately reflect on and manipulate the structural features of spoken language. That is, people who understand the nature of language rather than the ability to use language to communicate meaning are said to possess metalinguistic awareness. Metalinguistic awareness, therefore, refers to the ability of a person to consciously reflect on the nature of language using the following skills: (a) an awareness that language is more than just a collection of simple symbols, (b) an awareness that words are separable from their referents, and (c) an awareness that languages has a structure that can be manipulated.

Donaldson (2013) argues that metalinguistic awareness is essential in the development of reading skills in young children and a vital component in the development of learner's cognitive skills because of its documented relation to language ability, symbolic development and literacy skills according to Bialystok (2011). Among the popular concepts in the study of bilingualism is metalinguistic awareness, which could refer to learners' awareness of the language's phonological, morphological, syntactic systems and pragmatics (Tunmer, Herriman, $\&$ Nesdale, 1988). Amongst the four, phonological and word awareness are the two aspects of metalinguistic awareness that have gained the greatest attention in bilingual literacy research. Metalinguistic awareness in bilingualism is that, a person has the ability to objectify outside one language system and languages' rules, functions and structures. Studies reveal that when bilinguals have profound linguistic experience in two different language systems, they develop an articulated understanding of how languages work (Adesope, et al., 2010).

Bialystok and Barac (2012) related the degree of bilingualism, those who are proficient in two or more languages and those who are not, to aspects of linguistic awareness in terms of their demands on analysis of knowledge. Two studies are reported in which the respondents differ in the level of bilingualism to solve a metalinguistic task that made demands on their analysis and control. The hypotheses were that all bilinguals would perform better that those who are monolinguals in all metalinguistic tasks requiring high levels of control of processing and that full bilinguals would perform better than those who are partial bilinguals in all Metalinguistic task requiring high levels of analysis of knowledge. The results were largely consistent with these predictions. Galambos and Goldin-Meadow (1990) believe that experiencing two languages hastens the development of metalinguistic skills of young children. And so, bilingualism of the children is associated with their cognitive skills that are influenced by immediate speech community and media (Bialystok, 2011; Baker, 1996).

The theory of Cromdal (1999) emphasizes that children demonstrate syntactic awareness when they have sufficient levels on receptive vocabulary. That is, bilingual children who have higher combined perceptive vocabulary eventually outscored their less proficient bilingual peers in terms of syntactic measure. Wachira (1986) in Bialystok and Barac (2012) also cited an advantage of bilingualism, which states that since bilingual children have words in different languages to refer in a same thing, they can easily grasp the arbitrariness of a word and its 
referent, and can understand the sound of a word even if it has no relation with the meaning. While in terms of phonology bilinguals according to Yelland, Pollard, and Mercuri (1993) that limited exposure to second languages will result in phonological advantage. However, it may not be bilingualism alone, since languages affect the children's metalinguistic awareness, particularly, in terms of their awareness to the language's syntactic pattern. The importance of the learners' awareness to the language is also confirmed in the previous study. Surwanti and Hikmah (2019) revealed that students reading comprehension and language mastery are the other matters to be considered in the success of understanding the meaning of a reading text.

In the theory of Peal and Lambert (1962) in which they emphasized that bilinguals are based on the relationship between the proficiencies or awareness of the respective language that bilinguals master. That balance bilinguals are those who acquire similar degrees of proficiency of both languages while unbalance bilinguals are those whose proficiency or awareness in one language is higher than that of the other languages.

Flood and Menyuk (1983) indicated that reading achievement and age were positively related with metalinguistic ability. In their study, subjects were tested on non-grammatical, anomalous and ambiguous stimulus items in sentences and passages. It was found out that they were better to judge than to produce correct forms. Good readers' performance on oral tasks equaled their performance on written tasks by adulthood. Mora (2009) exclaimed that most children between the ages 6 and 8, begin to expand their metalinguistic awareness and start to recognize irony and sarcasm. This concept requires the child to understand the subtitles of an utterances of social and cultural context.

Recently, in the study of Dita (2009) on metalinguistic awareness, she used three tests to determine the Metalinguistic of Filipino bilingual children. This includes Language Arbitrariness, Phonological Awareness, and Vocabulary Knowledge. Dita's study, however, focused only on two languages (English and Filipino), while this study included a regional language (Cebuano).

Language Arbitrariness, according to Eviatar and Ibrahim (2012), imposes high demands on the control of attention and the capacity to detect and correct syntactic violations. Since the child is expected to suppress the expected answer and stick to the rule of the game, he/she would eventually know that language is arbitrary and subjected to change. Edwards and Christophersen (1988) reported that bilinguals have better performance in language arbitrariness than monolinguals.

Language is an arbitrary system because there is no significant relationship between the words of a given language and the concept it represents. The rules of the combination of signs to produce complete thought differ from one language to another and no sets of rules can claim the "right" one (Nor \& Rashid, 2018).

Phonological awareness is measured by children's ability to identify sounds of phonemes and to isolate and manipulate phonological segments. There are three versions of this task. The first two involve identification of first and last sound, respectively. The third consist of deleting a phoneme or a syllable and identifying the sound of the left phoneme or syllable after the deletion. It was Eviatar and Ibrahim (2012) who forwarded an extensive body of literature which discuss the relationship of phonological awareness to learners' levels of language facility, reading experience, and literacy.

Children who have well-developed Phonological awareness when it comes to school have a head start making sense of how sounds and letters operate into prints. This ability is important for using sound-letter effectively in writing and reading (Adams, et al., 2003).

Vocabulary knowledge is measured by the child's ability to explain a word on his own, drawing either on the function of the word or its general appearance. Vocabulary is a crucial tool to express ideas, feelings and learn about the world. Since words are foundation of learning, improving one's vocabulary becomes an educational priority (Massey et al., 2005). Limited vocabulary prevents students to comprehend a text. Therefore, vocabulary knowledge and academic achievements are strongly connected.

Eviatar and Ibrahim (2012) investigated the way the degree of difference between the linguistic systems influenced Metalinguistic awareness. In the study entitled "Bilingual is as bilingual does: Metalinguistic abilities of Arabic-speaking children", to which one hundred sixteen (116) Israeli children participated, it was revealed that there were no differences in the scores of Arab children and Russian-Hebrew bilinguals when it comes to arbitrariness. Besides, the scores of both groups are significantly different from the scores of Hebrew monolinguals. With regard to vocabulary, both Russian-Hebrew bilinguals and Hebrew monolinguals showed 
a significant difference in their scores comparing the grade 1 and kindergarten. However, no improvement took place with Arab children.

The study conducted by Eviatar and Ibrahim (2012) is related to the proposed study because both studies aim to investigate the metalinguistic awareness of bilinguals/multilinguals; however, the two studies differ in the respondents involved. The study of Eviatar and Ibrahim focused on the Metalinguistic awareness of bilingual and monolingual kindergartens and grade 1 pupils who were Hebrew-Russian bilinguals and Russian monolinguals while the present study focuses on the Multilingual Pupils of San Roque Central Elementary School in Davao City.

A relevant study was conducted in Thailand by Turbpaiboon and Onsuwan (2011). The study compares Thai children's metalinguistic awareness from different age groups and educational backgrounds. It suggested that the metalinguistic awareness of monolinguals and those who have sequential bilingualism does not differ. The metalinguistic development seems to emerge first age wise in structure meaning domain, then phonological, and lastly lexical. Interestingly, at around the ages of five and six, Thai monolinguals and bilinguals show a strong level of metalinguistic awareness in structure-meaning domain. They are able to produce grammatical sentences and also have the knowledge of syntactic rules. In both educational programs, the 8-9 year olds performed significantly better than that of the 5-6 year olds in all tasks except for the test on word arbitrariness.

The study conducted by Turbpaiboon and Onsuwan (2011) is related to the proposed study because both studies aim to investigate the metalinguistic awareness among children. However, the study differs on the number of languages spoken and chosen respondents because the study that was conducted in Thailand has two languages spoken namely: Thai and English and focused on children with different age groups 5-6 and 8-9 years old while the present study has three languages spoken namely: English, Filipino and Cebuano and will focus on the Grade 1 pupils with the age range from 6-8 years old.

In the study of Smith and Tager-Flusberg (1982) on metalinguistic awareness and language development", 36 preschoolers were given six metalinguistic tasks and two measures of language development: the Peabody Picture Vocabulary test and a sentence comprehension test. The children have been found to perform some metalinguistic judgment and the authors' content that metalinguistic awareness improves with age.

The study of Smith and Tager-Flusberg is related to the proposed study since both studies aim to investigate the metalinguistic awareness among children. However, the studies differ on the type of tests and the respondents because the study of Smith and Tager-Flusberg conducted 6 types of metalinguistic tests and focused on the preschoolers while the present study has 3 metalinguistic tests and focuses on the Grade 1 pupils.

Another study was conducted by Maxilom and Tecson (2009), investigating metalinguistic awareness of adolescent multilinguals in Cebu City. The results showed that the multilinguals who were highly proficient in Cebuano performed best in the control of linguistic processing in three languages. In the analysis of linguistic knowledge, the multilinguals who were highly proficient in three languages performed better in the error identification while the highly proficient in English and Cebuano performed better in the correction and grammatical error explanation.

The study of Maxilom and Tecson is related to the present study. The two studies only differ in the respondents and the type of metalinguistic tests given. Maxilom and Tecson focused on the metalinguistic awareness of adolescents who underwent error identification, correction and explanation while the present study focuses on the metalinguistic awareness of grade 1 pupils whose knowledge on Language Arbitrariness test, Phonology and Vocabulary will be tested.

Dita (2009) conducted a study on Metalinguistic awareness among children. The subjects were asked to answer three Metalinguistic tests namely: Language arbitrariness, Phonological awareness and Vocabulary test. The result shows that those who are full bilinguals outscored the partial bilinguals in all three tests conducted.

This study is related to the present study because both studies aim to investigate the Metalinguistic awareness on Filipino bilingual/multilingual children. However, the studies differ in their scope and limitation because the study of Dita focused on the kindergarten while the present study will focus on the Metalinguistic awareness of Grade 1 pupils in a pilot elementary school in Davao City, a city located in the southern part of the country. The participants of the present study speak English, Filipino, and Cebuano at home and in school. 


\section{RESEARCH METHOD}

This research followed the purely descriptive quantitative type of research which involves collection of quantitative information that can be tabulated along a continuum in numerical form, such as scores on a test. This is descriptive since this involves data, culled from participants' scores from an administered test, that can then be organized and tabulated to describe (Glass \& Hopkins, 1984) the metalinguistic awareness of multilingual pupils in the elementary level, specifically on Language Arbitrariness, Phonological Test and Vocabulary. The tests are modified from Dita's (2009) Metalinguistic Awareness test. The study involved thirty (30) multilingual learners whose ages range from 6-8 years and enrolled as grade 1 pupils.

\section{RESULTS AND DISCUSSION}

Students' Level of Metalinguistic Awareness in English, Filipino and Cebuano

This section shows how students performed in the test written in three languages.

Table 1. Level of Students' Metalinguistic Awareness in Three Languages

\begin{tabular}{cccccc}
\hline \multirow{2}{*}{ Metalinguistic Tests } & $\begin{array}{c}\text { Language } \\
\text { Arbitrariness }\end{array}$ & $\begin{array}{c}\text { Phonological } \\
\text { Awareness }\end{array}$ & Vocabulary & Overall \\
\hline \multirow{2}{*}{ English } & Mean & 5.87 & 21.13 & 6.37 & 20.3 \\
& Level & Average & High & High & Average \\
\multirow{2}{*}{ Filipino } & Mean & 4.9 & 21.87 & 7.17 & 22 \\
& Level & Average & High & High & Average \\
\multirow{2}{*}{ Cebuano } & Mean & 5.97 & 24.6 & 7.6 & 22.32 \\
& Level & High & Very High & High & Average \\
\hline
\end{tabular}

Table 1 shows that in English the multilingual pupils scored average in language arbitrariness (with mean score of 5.87), which means pupils were good in detecting syntactic violations; while phonological awareness (with a mean score of 21.13) and vocabulary (with a mean of 6.37) scored high, which means that they were outstanding in recognizing both initial and final phonemes and deletion task in a word and were outstanding in describing the functions and appearance of a given word. In Filipino, they scored average in language arbitrariness (with the mean score of 4.9), which means they were good in detecting syntactic violations; while in phonological awareness (with the mean score of 21.87) and vocabulary (with the mean score of 7.17) both scored high, which means that the multilingual pupils were outstanding in recognizing both initial and final phonemes and deletion task in a word and in describing the functions and appearance of a given word. While in Cebuano, they scored high in language arbitrariness (with the mean score of 5.97) and vocabulary (with the mean score of 7.6), which means that the pupils were outstanding in detecting syntactic violations and in describing the functions and appearance of a given word; while in phonological awareness, the pupils scored very high with a mean score of 24.6 , which means that they were excellent in recognizing both initial and final phonemes and deletion task in a word.

The results confirmed the study of Cromdal (1999) that children who are proficient on receptive vocabulary have better performance in syntactic awareness measure. That is, bilingual children who have higher combined perceptive vocabulary eventually outscored their less proficient bilingual peers in terms of syntactic measure. This also confirms the study of Smith and Tager-Flusberg (1982) which also found out that bilingual children have good level of metalinguistic awareness especially in vocabulary.

And these findings were verified by the present study since all grade 1 multilingual pupils were found to be either on the average or high level in language arbitrariness even if they are still first graders. The findings also support the contention of Vygotsky (1986) in Bialystok and Barac (2012) in the advantage of bilingualism, which states that because bilingual children have words in different languages to refer to a same thing, they can easily grasp the arbitrariness of a word and its referent, and can understand the sound of a word even if it has no relation with the meaning.

The present study confirms Maxilom and Tecson's (2009) study. In their study, in terms of English and Cebuano, pupils scored high in the Metalinguistic tasks like correction and grammatical identification. The findings in the present study also shows that the multilingual pupils scored high in English and Cebuano in terms of language arbitrariness. The findings also affirmed the theory of Yelland, Pollard, and Mercuri (1993) that even limited exposure to 
second or third language will result in phonological advantage. However, it may not be bilingualism per se, but the finding reminds us that languages affect children's Metalinguistic awareness, particularly, in terms of syntactic awareness, considering that the children's first language/s has/have entirely different syntax compared to English. These findings were confirmed by the result of the present study since the grade 1 multilingual pupils were established to score high in phonological awareness in all three languages. And so, the bilingualism of the children is associated with their cognitive skills that are influenced by the immediate speech community and media (Bialystok, 2011; Baker, 1996) since the media of today has a big impact on children's learning most especially in second language learning.

The result also affirms the theory of Mora (2009) that most children between the ages 6 and 8 , begin to expand their metalinguistic awareness and start to recognize irony and sarcasm. This concept requires the child to understand the subtitles of the utterance's social and cultural context. That in this crucial stage of learning, language is not the only factor in learning or acquiring vocabulary. The results also support the theory of Galambos and Goldin-Meadow (1990) who believe that the experience in two languages hastens the development of metalinguistic skills of young children. That is, the difference between languages may also affect children's syntactic awareness and that being bilingual helps detect grammatically correct sentences better. And thus, higher receptive vocabulary score in Cebuano does not necessarily translate higher syntactic awareness into other languages that they are rarely exposed. This is similar with the findings of the present study since the grade 1 multilingual respondents got high score in Cebuano, which is their mother tongue, compared to English and Filipino. The findings also confirm the study of Dita (2009) in which the pupils scored higher in Filipino rather than in Cebuano because of the different exposure and learning in the two languages. The results were verified by the present study because they scored higher in their mother language, Cebuano, than English and Filipino.

In the tests conducted to the multilingual pupils, they scored average in all three languages. Among the three versions, the grade 1 multilingual pupils got the highest mean of 22.32 in the Cebuano test; followed by the Filipino version with the mean of 22 and lastly, the English test since it recorded the lowest mean of 20.3. This means, in all three tests, the multilingual pupils are good in analyzing language and its subparts: the languages' structure, sound pattern, function and appearance. This finding supports the theory of Bialystok (2011) in bilingualism or multilingualism that those who are proficient in two or more languages are more likely to perform linguistically better than that of monolinguals. That is, it involves speakers who have native-like control of a language when they are interacting with other people and have as much knowledge and control over language as they have of the other languages. From the findings, it could be deduced that overall, the pupils were indeed multilinguals and they scored average in all three tests. This proves their control of these three languages despite the frequency of exposure.

\section{Statistical Difference of Students' Level of Metalinguistic Awareness in the Administered Tests}

Table 2 shows the difference in the performance of students given the use of different languages in the test.

Table 2. Significant Difference between the Students' level of Metalinguistic Awareness in English, Filipino and Cebuano in all Tests

\begin{tabular}{ccccc}
\hline \multicolumn{2}{c}{ Metalinguistic Test } & $\begin{array}{c}\text { Language } \\
\text { Arbitrariness }\end{array}$ & Phonological Awareness & Vocabulary \\
\hline English & Sig. Value & .000 & .011 & .075 \\
& Remarks & Sig. Different & No Sig. Different & Sig. Different \\
Cebuano & Sig. Value & .000 & .012 & .018 \\
& Remarks & Sig. Different & Sig. Different & Sig. Different \\
Filipino & Sig. Value & .026 & .226 & .014 \\
& Remarks & No Sig. Differ. & Sig Different & No Sig. Differ. \\
\hline
\end{tabular}

The findings in the Cebuano test reveals that there is significant difference in terms of language arbitrariness (with significant value of .000); phonological awareness (with significant value of .012) and vocabulary (with the significant value of .018) since the significant value of the mean scores of the grade 1 multilingual pupils was higher than the significant value of 0.05 . This indicates that the extreme heterogeneity of pupils' metalinguistic awareness was apparent in the Cebuano test, even if it is their native language. This could be due to different exposures to the language or to varied linguistic experiences of the grade 1 multilingual pupils when it 
comes to learning Cebuano. As indicated by their scores, the researcher was able to realize that some pupils have enough knowledge while there were others who lack awareness on Cebuano language arbitrariness, and vocabulary.

Based on the result in the English test, the participants' scores in terms of language arbitrariness (with significant value of .000); phonological awareness (with significant value of .011 ), and vocabulary (with the significant value of .075). The mean scores of the grade 1 multilingual pupils when it comes to language arbitrariness and phonological awareness are significantly different since the significant values were less than the significant value of 0.05 . This means that children has different metalinguistic awareness in language arbitrariness and phonological awareness while in terms of vocabulary, children have almost the same level of metalinguistic awareness.

In the Filipino test, on the other hand, the scores of grade 1 multilingual pupils are significantly different only when it comes to vocabulary (with significant value of .014). This means that they have different Metalinguistic awareness; whereas, in the Filipino test for language arbitrariness (with significant value of .026); and phonological awareness (with the significant value of 0.226 ), students' scores are not significantly different. This implies that in terms of language arbitrariness and phonological awareness, the multilingual pupils have almost the same metalinguistic awareness. The findings imply that there is no significant difference between the learners' metalinguistic awareness in English and Cebuano in terms of language arbitrariness, which confirms the study of Eviatar and Ibrahim (2012) in their study of Arab children and Russian-Hebrew bilinguals. The findings also affirm the theory of Peal and Lambert (1962) in which they emphasized that bilinguals are based on the relationship between the proficiencies or awareness of the respective language that bilinguals master. Balanced bilinguals are those who acquire are those who acquire similar degrees of proficiency of both languages while unbalanced bilinguals are those whose proficiency or awareness in one language is higher than the other languages. This helps explain the significant difference between learners' metalinguistic awareness in three different languages.

Table 3. Significant Difference in the Overall Level of Metalinguistic Awareness in English, Filipino and Cebuano

\begin{tabular}{ccl}
\hline Metalinguistic Tests & Sig. Value & \multicolumn{1}{c}{ Remarks } \\
\hline English & .000 & There is significant difference. \\
Filipino & .000 & There is significant difference. \\
Cebuano & .000 & There is significant difference. \\
\hline
\end{tabular}

Overall, the awareness of multilingual pupils in each language differs from one to another. This means further that each student has diverse linguistic experience and that they do not have similar exposure to the phonological, morphological, and syntactic structures in English, Filipino, and Cebuano.

This supports the claim of Genesee (2015) that bilingual children can acquire the same proficiency in all aspects of their two languages over time. Bilingual children may have different patterns of development in certain aspects of language in the short term, but children generally acquire the same proficiency in the sound system and morphological-syntactic pattern of the two languages, when given sufficient input. Bilingual children's overall proficiency in each language reflects the amount of time they spend on each. The theory was verified with the result that the grade 1 multilingual pupils have different awareness in each language they were proficient based on the exposure they have in the multilingual environment. Parents can ensure that their children achieve full proficiency in both languages if they are supportive of the idea that children need to be provided with rich experience with each language, especially with the language that might otherwise not get strong support in the extended community. It is, therefore, important that parents continue to use their native language so that they expose their child to varied and rich ways of using the language.

In summary, this study reveals that in both English and Filipino, the Grade 1 multilingual learners scored average in language arbitrariness and high in phonological and vocabulary; while in Cebuano, they scored high in language arbitrariness and vocabulary and very high in terms of phonological awareness. The overall level of young school-age children's metalinguistic awareness in English, Filipino, and Cebuano is average when analyzing language and its subparts: syntactic structure, sound pattern, function and appearance in all 
three languages. There is significant difference between the learners' metalinguistic awareness in English and Filipino in all the tests; while in Cebuano, there is no significant difference between the learners' metalinguistic awareness in all three tests. Finally, there is significant difference between the overall level of metalinguistic awareness in English, Filipino and Cebuano.

\section{CONCLUSION}

This study concludes that Grade 1 multilingual learners still need to improve their linguistic experience to English and Filipino particularly in the identification of syntactic errors, since they will likewise be using these languages in their succeeding academic endeavors. The study further posits that the young school-age children's metalinguistic awareness in Cebuano helps them in fulfilling their linguistic tasks in Filipino and English. Based on the results, the study recommends that teachers and curriculum designers can provide strategies and lessons that would enhance learners' metalinguistic awareness most especially in terms of language arbitrariness in English and Filipino. Since there is significant difference in English and Filipino in all three tests, parents and teachers should ensure that the pupils achieve full proficiency in all three languages by providing rich experiences in these languages. And to develop this study to know further the factors that would best develop learners' metalinguistic awareness and its impacts to young school-age children's readiness for other linguistic demands.

\section{REFERENCES}

Adesope, O. O., Lavin, T., Thompson, T., \& Ungerleider, C. (2010). A systematic review and meta-analysis of the cognitive correlates of bilingualism. Review of Educational Research, 80(2), 207-245. doi: 10.3102/0034654310368803

Adams, M. J., Foorman, B. R., Lundberg, I., \& Beeler, T. (2003). Phonemic awareness in young children: A classroom curriculum. Baltimore, MD: Brookes.

Baker, M. (1996). Corpus-based translation studies: The challenges that lie ahead. Benjamins Translation Library, 18, 175-186. doi: 10.1075/btl.18.17bak

Baten, K., Hofman, F., \& Loeys, T. (2011). Cross-linguistic activation in bilingual sentence processing: The role of word class meaning. Bilingualism: Language and Cognition, 14(3), 351-359. doi: 10.1017/S1366728910000246

Beceren, S. (2010). Comparison of metalinguistic development in sequential bilinguals and monolinguals. The International Journal of Educational Researchers, 1(1), 28-40. Retrieved from http://ijer.penpublishing.net/makale/33

Bialystok, E. (2011). Reshaping the mind: the benefits of bilingualism. Canadian Journal of Experimental Psychology/Revue canadienne de psychologie expérimentale, 65(4), 229. doi: $10.1037 / \mathrm{a} 0025406$

Bialystok, E., \& Barac, R. (2012). Emerging bilingualism: Dissociating advantages for metalinguistic awareness and executive control. Cognition, 122(1), 67-73. doi: 10.1016/j.cognition.2011.08.003

Cromdal, J. (1999). Childhood bilingualism and metalinguistic skills: Analysis and control in young Swedish-English bilinguals. Applied Psycholinguistics, 20(1), 1-20. doi: 10.1017/S0142716499001010

Dita, S. (2009). The metalinguistic awareness of Filipino bilingual children. The Philippine ESL Journal, 3. $\quad$ Retrieved r from https://www.researchgate.net/publication/291798975_The_metalinguistic_awareness_o f_Filipino_bilingual_children

Donaldson, M. (2013). A study of children's thinking. Abingdon: Routledge.

Edwards, D., \& Christophersen, H. (1988). Bilingualism, literacy and meta-linguistic awareness in preschool children. British Journal of Developmental Psychology, 6(3), 235-244. doi: 10.1111/j.2044-835X.1988.tb01097.x

Eviatar, Z., \& Ibrahim, R. (2012). Multilingualism among Israeli Arabs, and the neuropsychology of reading in different languages. In Current issues in bilingualism. Springer-Dordrecht Heidlberg London pp 57-74. 
Flood, J., \& Menyuk, P. (1983). The development of metalinguistic awareness and its relation to reading achievement. Journal of Applied Developmental Psychology, 4(1), 65-80. doi: 10.1016/0193-3973(83)90059-X

Galambos, S. J., \& Goldin-Meadow, S. (1990). The effects of learning two languages on levels of metalinguistic awareness. Cognition, 34(1), 1-56. doi: 10.1016/0010-0277(90)90030$\mathrm{n}$

Genesee, F. (2015). Myths about early childhood bilingualism. Canadian Psychology/Psychologie Canadienne, 56(1), 6. doi: 10.1037/a0038599

Glass, G. V \& Hopkins, K.D. (1984). Statistical Methods in Education and Psychology, 2nd Edition. Englewood Cliffs, NJ: Prentice-Hall.

Goetz, P. J. (2003). The effects of bilingualism on theory of mind development. Bilingualism: Language and Cognition, 6(1), 1-15. doi : 10.1017/S1366728903001007

Grosjean, F. \& Li, P. (2013). The Psycholinguistics of bilingualism. Malden, MA \& Oxford: Wiley-Blackwell.

Hill, V. (1998). Integrating the theories of metacognition and metalinguistics to help in the understanding of literacy development to promote academic success. Text in education and society, 106-125. doi: 10.1142/9789812815781_0007

Massey, A. J., Elliott, G. L., \& Johnson, N. K. (2005). Variations in aspects of writing in 16+ English examinations between 1980 and 2004: Vocabulary, spelling, punctuation, sentence structure, non-standard English. Cambridge: Cambridge Assessment. Retrieved from https://www.cambridgeassessment.org.uk/.../109738-variations-inaspects-of- writing-in-16-english-examinations-between-1980-and-2004-vocabulary

Maxilom, R. M. R., \& Tecson, C. A. (2009). Metalinguistic awareness of adolescent multilinguals in Cebu City. Philippine Quarterly of Culture and Society, 37(4), 207230.

Mora, J. K. (2009). Metalinguistic awareness as defined through research. Retrieved from http://www. moramodules. com/Pages/MetalingHandout.

Nor, N. M., \& Ab Rashid, R. (2018). A review of theoretical perspectives on language learning and acquisition. Kasetsart Journal of Social Sciences, 39(1), 161-167. Retrieved from http://www.thaiscience.info/Journals/Article/TKJS/10989582.pdf

Peal, E., \& Lambert, W. E. (1962). The relation of bilingualism to intelligence. Psychological Monographs: general and applied, 76(27), 1. doi: 10.1037/h0093840

Skutnabb-Kangas, T. (1984). Bilingualism or not: The education of minorities (Vol. 7). Avon: Multilingual Matters Ltd.

Smith, C. L., \& Tager-Flusberg, H. (1982). Metalinguistic awareness and language development. Journal of Experimental Child Psychology,34(3), 449-468. doi: 10.1016/0022-0965(82)90071-6

Surwanti, D. \& Hikmah, I. (2019). Improving students' awareness of functional literacy. English Language Teaching Educational Journal, 2(2), 79-89. doi : 10.12928/eltej.v2i2.1307

Tunmer, W. E., Herriman, M. L., \& Nesdale, A. R. (1988). Metalinguistic abilities and beginning reading. Reading research quarterly, 134-158. doi: $10.2307 / 747799$

Turbpaiboon, P., \& Onsuwan, C. (2011). “A comparative study of Thai children's metalinguistic awareness from different age groups and educational programs." In Sagaravasi and ML. Abhakorn (eds.), Proceedings of the 2nd International Conference on Language and Communication, The Graduate School of Language and Communication, The National Institute of Development Administration (NIDA), Thailand. 45-52. Retrieved from https://arts.tu.ac.th/teacher_linguistics02.html 
Wachira, A.W. (2006). Multilingualism in Kenya: Focus on language use and its implications. In: TRANS. Internet-Zeitschrift für Kulturwissenschaften. No. 16/2005. Retrieved from http://www.inst.at/trans/16Nr/03_2/wachira16.htm

Yelland, G. W., Pollard, J., \& Mercuri, A. (1993). The metalinguistic benefits of limited contact with a second language. Applied psycholinguistics, 14(4), 423-444. doi: $10.1017 / \mathrm{S} 0142716400010687$ 